\title{
Os saberes e o fazer pedagógico: uma integração entre teoria e prática
}

\section{Knowledges and pedagogical practice: an integration between theory and practice}

\author{
Annatália Meneses de Amorim Gomes* \\ Conceição Maria de Albuquerque** \\ Ana Maria Fontenelle Catrib*** \\ Raimunda Magalhães da Silva**** \\ Marilyn Kay Nations* \\ Mirna Frota de Albuquerque ${ }^{* * * * * *}$
}

\begin{abstract}
RESUMO
O saber-fazer docente desperta o interesse dos educadores que tratam deste tema sob diferentes ópticas: competência do professor; integração do conhecimento subjacente do aluno; do professor reflexivo-crítico; da proposta de educação libertadora e prática política; e reconhecimento da complexidade da educação e reflexão sobre a fragmentação das disciplinas, dificultando a interdisciplinaridade. Este estudo descritivo qualitativo trata de um processo de ensino a partir de análises teóricas e empíricas, proposto por Edgar Morin, ocorrido na disciplina Didática, no Mestrado em Educação·em Saúde da UNIFOR, em 2004. Participaram da pesquisa vinte mestrandos de várias categorias profissionais. Os resultados demonstram que a dinâmica empregada propiciou a integração, maior compreensão dos conceitos e obtenção de
\end{abstract}

* Psicóloga, Assistente Social, Mestranda em Educação em Saúde da Universidade de Fortaleza - UNIFOR. Bolsista da FUNCAP.

** Enfermeira. Mestranda em Educação em Saúde. UNIFOR.

**** Doutora em Educação. UNIFOR.

***** Doutora em Enfermagem. UNIFOR.

***** Doutora em Antropologia Médica. UNIFOR.

******** Doutora em Enfermagem. UNIFOR. 
GOMES, A. M. A. et al. Os saberes e o fazer pedagógico:...

clima descontraído para aprendizagem. Concluímos que estratégias tais como jogo; dinâmicas grupais e psicodrama pedagógico favorecem a participação e a expressão de sentimentos, permitem a interação, assimilação e compartilhamento das experiências na elaboração coletiva do conhecimento. Palavras-chave: ensino-aprendizagem; didática; prática pedagógica.

\begin{abstract}
The teaching know-how arouses the interest of educators who deal with this subject from different points of view: teacher's competence; integration of the student's hidden knowledge; the reflexive-critical teacher; proposal for liberating education and political practice; the recognition of educational complexity and reflection on the fragmentation of disciplines which make difficult the interdisciplinariety. This descriptive-qualitative study is about a teaching process based on theoretical and empirical analyses, proposed by Edgar Morin, and took place in the discipline of didactics from the Master Course of Health and Education at UNIFOR in 2004. Twenty Master students from several professional categories participated in the event. The outcomes showed that the dynamics applied to the study provided greater understanding of concepts, integration, as well as relaxing environment concerning the learning process. It is concluded that strategies such as games, group dynamics and pedagogical psychodrama provide participation and the expression of feelings, interaction, assimilation and experiences shared through the collective construction of knowledge.

Key-words: teaching-learning; didactics; pedagogical practice.
\end{abstract}

\title{
Introdução
}

O saber-fazer do professor desperta o interesse dos estudiosos que tratam deste tema sob diferentes perspectivas: a competência do professor e a integração do conhecimento subjacente do aluno (PERRENOUd, 2002); do professor reflexivo-crítico (SHON, 2000; ALARCÃo, 2003); da proposta de educação libertadora e prática política (FREIRE, 1999) e do reconhecimento da complexidade da educação e reflexão sobre a fragmentação das disciplinas, dificultando a interdisciplinaridade (MORIN, 2003, 2004; FAZENDA, 1998).

Todas essas abordagens se complementam na tentativa de responder aos desafios que se expressam no universo do ensino-aprendizagem, no 
qual a prática pedagógica constitui uma das categorias fundamentais da atividade humana, rica em valores e significados, pois a questão metodológica se torna, muitas vezes, tão essencial quanto o conhecimento (LEAL, 2004).

A formulação do conhecimento torna-se uma ocasião de alargamento ativo do aprendizado do aluno, de sua prática, que pode ser predominantemente perceptiva, motora ou reflexiva. Isso poderá ser organizado mediante ações tais como estudo de textos, vídeos, pesquisas, estudo individual, debates, grupos de trabalhos, seminários e práticas nas quais se exercitam as relações que possibilitam identificar, pela avaliação, como se elabora o objeto de conhecimento. Daí, então, a necessidade da escolha de estratégias com várias e expressivas práticas sugeridas ao aluno, objetivando ultrapassar seus dados iniciais sobre o objeto do conhecimento (ANASTASIOU, 2004).

Tardif (2002, p. 128) propõe uma pedagogia que priorize a "tecnologia da interação humana, colocando em evidência, ao mesmo tempo, a questão das dimensões epistemológicas e éticas", apoiada necessariamente em uma visão de mundo, de homem e sociedade. Neste sentido, uma prática pedagógica precisa ter dinâmica própria, que lhe permita o exercício do pensamento reflexivo, conduza a uma visão política de cidadania e que seja capaz de integrar a arte, a cultura, os valores e a interação, propiciando, assim, a recuperação da autonomia dos sujeitos e de sua ocupação no mundo, de forma significativa.

No que diz respeito às relações entre pessoas e a intersubjetividade presente em todo contato humano, Moreno (1959) propõe, a partir de sua vivência e prática com grupos, teoria e metodologia psicodramáticas, as quais negam a repetição de conteúdos e pedem a aprendizagem de ações, que se adquirem na experiência e nas relações interpessoais. Neste contexto da prática pedagógica interativa, é utilizado o psicodrama pedagógico, a partir do pressuposto de que este propicia o resgate da espontaneidade por meio da ação dramática (GOMES, 2002). Como método didático, garante a aquisição do conhecimento no plano intuitivo e intelectual, permitindo o manejo do grupo como unidade (ROMAÑA, 1987; 1996).

Sobre a importância desta atuação participativa mais abrangente do aluno no decurso do ensino, Schon (2000, p. viii) comenta que o professor deve fazer uso de um conjunto de processos que combinem "o ensino da ciência aplicada com a instrução, no talento artístico da reflexão-ação", mobilizando, além da lógica, manifestações de talento, intuição e sensibilidade artística. 
Corroborando esta visão, Anastasiou (2004) confirma que a função do professor é, então, de provocar, instigar, valer-se dos alunos para elaborar uma ligação com o objeto de aprendizagem que, em algum estádio, consinta em uma carência deles, auxiliando-os a tomar consciência das necessidades socialmente existentes na sua formação. Isso só acontecerá num momento propício à integração, um certo "clima de compartilhar", tendo como um ingredientes especiais à abertura a problematização e a discordância adequada aos procedimentos de pensamento crítico e crescimento.

Ainda sobre as possibilidades de significação da prática reflexiva, Silva, 2002 e Araújo, 2002 destacam o seu caráter heterogêneo e plural, o qual possibilita a inter-relação dos diferentes saberes, produzindo conhecimentos em articulação com o contexto sócio-político, econômico e cultural, que resulta numa intervenção na realidade a partir da relação com o mundo da experiência humana, com sua bagagem de valores, interesses sociais, afetos, conotações diferenciadas e cenários políticos.

Em outra perspectiva, Morin (2003) prioriza a complexidade da educação, discorrendo principalmente sobre os pressupostos e saberes que ele denomina como os sete saberes necessários à educação do futuro: as cegueiras do conhecimento; o erro e a ilusão; os princípios do conhecimento pertinente; ensinar a condição humana; ensinar a identidade terrena; enfrentar as incertezas; e ensinar a compreensão e a ética do gênero humano. Enfatiza a problemática da fragmentação das disciplinas e dos currículos, dificultando a interdisciplinaridade na educação. Evidencia o desenvolvimento de uma educação que desempenha a inter-relação do indivíduo/espécie/sociedade de forma indissociável, pois, ao mesmo tempo, recobra a identidade do sujeito, fazendo-o numa profunda relação com os outros e o planeta. Cada um desses saberes será detalhado no desenrolar deste ensaio.

Identificada ao pensamento deste autor, Leal $(2004$, p. 2) considera que o saber-fazer é sobretudo saber SER um educador, todos os dias, de qualquer modo, de todos os jeitos, assumindo o compromisso de formar alunos para serem sujeitos, participantes e autores da história: "é necessário não só conhecer a ciência, mas ter alma de educador, voltando-se para a vida e para as utopias".

Assim podemos perceber que não basta refletir sobre as relações entre ser e fazer, pois é preciso também analisar a inter-relação do ter com o ser. O ter-conhecimento comporta um valor importante, constituindo-se meio e instrumento para ser mais, aperfeiçoar e realizar o ser professor e aluno num processo de troca e interação de seus sentidos e significados em 
dado contexto histórico. O ter e o fazer devem servir para SER mais e melhor, a fim de que o ensino-aprendizagem contribua para a conscientização reflexivo-crítica dos sujeitos históricos e se recriem as possibilidades de uma pedagogia humanizadora, "numa perspectiva crítica e transformadora" (PIMENTA; ANASTASIOU, p. 81, 2002).

É neste contexto da discussão dos saberes e da prática pedagógica que este estudo se inseriu e se desenvolveu, a partir de alguns questionamentos: será que, integrando o pensamento de Edgar Morin com situações e momentos vivenciais, isto favoreceria o processo ensino-aprendizagem? Como tratar de um assunto tão extenso, filosófico e complexo de modo que as pessoas se envolvessem e apreendessem os seus significados? Com base nestas questões buscamos desenvolver um trabalho que facilite a aprendizagem e compreensão dos sete saberes de Edgar Morin pela integração de: reflexão-ação, interação entre facilitador-aluno, aluno-aluno, sentimentos, percepções e conhecimento dos pressupostos do autor na prática pedagógica de seminário.

\section{Caminho percorrido}

Trata-se de um estudo descritivo-exploratório, com a finalidade de descrever um processo de ensino-aprendizagem no qual se processaram análises empíricas e teóricas.

O estudo originou-se na disciplina Metodologia do Ensino Superior, do Curso de Mestrado em Educação em Saúde, da Universidade de Fortaleza (UNIFOR). O programa desta disciplina foi dividido em três unidades temáticas: organização do ensino-aprendizagem, formulação da aprendizagem-saber e aprender e, por último, avaliação e o processo ensino-aprendizagem. Os conteúdos referentes à visão de quatro autores sobre organização do ensino (Edgar Morin), competência profissional/prática reflexiva (Perrenoud), docência do ensino superior (Pimenta) e professores reflexivos (Alarcão) foram divididos, por processo de escolha, em 5 seminários temáticos trabalhados pelos vinte alunos que compõem a turma.

A composição da turma é multidisciplinar, englobando áreas diversas do conhecimento, como Psicologia, Enfermagem, Terapia Ocupacional, Educação Física, Fisioterapia, Pedagogia, Odontologia e Fonoaudiologia. 
A estratégia de ensino adotada baseou-se em jogos e dinâmicas, objetivando facilitar o ensino-aprendizagem, tendo sido elaborada no decorrer da leitura e discussão dos conteúdos dos capítulos do livro de Edgar Morin (2003), Os Sete saberes necessários à educação do futuro, esteada no referencial psicodramático, a partir de vivências anteriores de ensino, da vida cotidiana e do conhecimento acessado pelas leituras, deixando-se fluir e conduzir pelo que o autor na sua lógica de raciocínio e intencionalidade procurava transmitir por meio das palavras escritas.

O objetivo desta metodologia de trabalho consistiu em fazer com que cada aluno experimentasse de maneira integral o referencial apontado por Morin (2003), propiciando a participação do corpo - movimento, da mente - reflexão, sentimentos - emoções, integração - relação com o outro e o planeta e resgate de valores, favorecendo, assim, o significado do todo. Para melhor captação dos resultados, todo o Seminário foi filmado, e então houve a transcrição de algumas das falas de participantes.

Os resultados foram apresentados conforme o desenvolvimento do Seminário, correlacionando os sete saberes e a dinâmica proposta aos alunos para a compreensão e análise de cada saber.

Os participantes foram informados sobre o estudo, tendo sido consultados previamente, demonstrando interesse na sua participação. Suas identificações foram respeitadas sendo preservados o sigilo e privacidade.

\section{Os sete saberes e o fazer pedagógico: relato de experiência}

O início do trabalho ocorreu pela apresentação das facilitadoras, do autor e do livro, que fundamentaram o Seminário: "Edgar Morin e os sete saberes necessários a educação do futuro", programação e dinâmica do seminário.

Após este momento introdutório, iniciou-se o aquecimento do grupo, mediante convite aos alunos a participarem de uma viagem no tempo a partir do tema. Um relógio desenhado com cores variadas na parede, cada uma representando um saber específico, facilitava a espontaneidade e a fluidez do pensamento. Na ocasião, refletimos na idéia de que o tempo é o de agora, pois urge que mudanças ocorram no paradigma educacional na prática. A cada troca de saber, o facilitador se referia ao "relógio do tempo" 
e o processo continuava pela introdução de uma dinâmica ou jogo relacionado ao conteúdo.

Para cada saber, procedeu-se a uma dinâmica própria: primeiro saber - as cegueiras do conhecimento: o erro e a ilusão - reflexão e percepção; segundo saber - Princípios do conhecimento pertinente - construção e (des)construção; terceiro saber - ensinar a condição humana - teatro do improviso; quarto saber - ensinar a identidade terrena - com a vida nas mãos; quinto saber - enfrentar as incertezas: simulação de improviso; sexto e sétimo saberes - ensinar a compreensão e a ética do gênero humano integração.

Ao final de cada momento vivencial, era feita uma construção conceitual dialogada sobre o saber em cena, integrando uma síntese exposta pelo facilitador e os conhecimentos e vivências dos alunos numa síntese compreensiva.

A roda em movimento, após a reflexão do último saber, propiciou por último, uma avaliação baseada nos sentimentos e julgamentos sobre o seminário, finalizando com um abraço representando a necessidade da afetividade e construção de uma prática educativa que inclua o ser humano em toda a sua expressividade. Em seguida cada um desses momentos é descrito e analisado.

\section{Viagem no relógio do tempo de agora e do futuro}

Primeiro saber: as cegueiras do conhecimento - o erro e a ilusão - reflexão e percepção

A educação deve mostrar que não há conhecimento que não esteja em algum grau ameaçado pelo erro e pela ilusão (MORIN, 2003 p. 19).

No primeiro saber, a educação deve enfrentar o problema que todo conhecimento comporta - o risco do erro e da ilusão, sendo imprescindível fazer conhecer o que é conhecer, ou seja, estudar as características psíquicas e culturais que constituem o conhecimento humano. 
Para Morin (2003), o processo de conhecer não é mero reflexo das coisas ou do mundo externo, pois todas as percepções são, ao mesmo tempo, traduções e reconstruções cerebrais com base em estímulos ou sinais captados e codificados pelos sentidos.

Com arrimo neste pensamento, foi propiciado aos alunos um momento de reflexão perceptivo pela apresentação da figura de "Monalisa", tendo sido feita a seguinte pergunta: o que você vê? Deveriam ser feitas anotações sobre as representações e impressões da figura. Ao final, quatro voluntários expressaram suas percepções, cada um, a partir de seu referencial, apontou aspectos diferentes como uma face que encontra o novo e o velho, uma teia, a diversidade, uma imagem de poder:

O novo e o velho se encontrando em uma mesma face. (Mestrando I) Vejo uma diversidade, mantendo o tradicional em uma nova postura de vida no nosso dia a dia. (Mestrando J).

A complexidade promovendo uma teia entre o novo e o velho. (Mestrando C).

Uma imagem do poder figurando a contradição ou encontro entre o velho e o novo, o ontem e o hoje. (Mestrando $\mathrm{H}$ ).

$\mathrm{Na}$ forma de cada participante perceber a realidade, encontram-se embutidas as projeções dos desejos, a afetividade, experiências anteriores com a imagem, levando a formas diferenciadas de apreender o fenômeno e, por isso, multiplicam-se os riscos de erro. Isso desperta o cuidado de o conhecimento científico não poder tratar sozinho dos problemas epistemológicos, filosóficos e éticos, como destaca o autor. Perceber essas implicações é fundamental para quem se propõe tornar-se um pesquisador-educador.

Segundo saber: princípios do conhecimento pertinente - construção e (des)construção

O conhecimento das informações ou dos dados isolados é insuficiente. É preciso situar as informações e os dados em um contexto para que adquiram sentidos (MORIN, 2003, p. 65).

O segundo saber diz respeito à desfragmentação do conhecimento. Sob esse aspecto, entende Morin (2004) que há inadequação cada vez mais 
agravada entre os saberes separados, fragmentados, compartimentados entre disciplinas e as realidades ou problemas da realidade global, complexa e multidimensional. Acrescenta o autor que o desenvolvimento disciplinar das ciências, apesar de trazerem as vantagens da divisão do trabalho, geraram a hiperespecialização, impedindo de ver o global, pois, espedaçando em parcelas o saber e fragmentando os problemas, inibem as possibilidades de reflexão e compreensão do todo.

Corroborando o autor, Fazenda (1998) destaca na análise do contexto histórico da prática educativa a sua fragmentação em vários aspectos, evidenciando a importância do agir e do fazer fundados numa perspectiva de totalidade.

A sua proposta consiste em inserir o objeto do conhecimento no texto e contexto dos problemas, posicionando-os cada vez mais no âmbito planetário, considerando a sua multidimensionalidade, a complexidade, interdependências e inter-relações todo-parte em seu conjunto.

Na dinâmica grupal, para a compreensão deste saber, utilizamos a representação de dois quebra-cabeças com figuras humanas, distribuídos em dois grupos de alunos. As peças representavam a fragmentação do conhecimento e/ou superespecialização. Os alunos deveriam montar a estrutura a partir das peças separadas e divididas entre os grupos.

Rapidamente esta montagem foi elaborada e procedemos à reflexão, com alguns comentários sobre como os profissionais de saúde são levados a perceber e a estudar o processo saúde-doença de forma compartimentada, assim como perdem em variadas situações a possibilidade de relacionar-se com os usuários de forma integral e individualizada, comprometendo a sua atuação na prática de forma mais humanizada.

Terceiro saber: ensinar a condição humana - teatro do improviso

O ser humano é a um só tempo físico, biológico, psíquico, cultural, social, histórico. (MORIN, 2003, p. 15).

O centro do pensamento do autor neste saber sobre o ensino da condição humana é reconhecer a unidade da identidade comum aos humanos, a sua diversidade e a complexidade da natureza humana. Para Morin (2003), a condição humana como unidade complexa deveria ser o objeto essencial de todo o ensino, mas esse propósito encontra-se impossibilitado pela desintegração das disciplinas. 
GOMES, A. M. A. et al. Os saberes e o fazer pedagógico:...

Para superar a fragmentação, a educação deve conduzir ao conhecimento da consciência do destino da espécie humana, individual, social e histórico, tudo entrelaçado e inseparável. Para que a prática educativa, entretanto, se torne totalidade e alcance o ser, é preciso, segundo Fazenda (1998), que ela se torne o lugar de um projeto educacional com finalidades baseadas em valores, articulando propostas e planos de ação com fundamento uma intencionalidade, desvendando sua própria ideologia e mediando o mundo do trabalho, a vida social e a cultura.

$\mathrm{Na}$ continuidade do processo interacional com os alunos, as facilitadoras neste momento tornaram-se protagonistas de uma cena em que colocaram uma cartela nas costas deles, com o nome de cada dimensão da natureza humana: física, biológica, psíquica, cultural, social e histórica. À medida que pronunciavam estes nomes, virando-se para a platéia, faziam um gesto que a representava, finalizando de mãos dadas com a frase: "nós somos unidade e complexidade na diversidade, nós somos o ser humano". Ao final, explicamos o pensamento do autor, definindo o conceito e apontando as formas de enfrentamento para uma visão mais integral do ser humano.

Quarto saber: ensinar a identidade terrena - com a vida nas mãos

Todos os seres humanos partilham um destino comum (MORIN, 2003, p. 16).

Este saber nos remete a uma profunda reflexão sobre a relação do homem com o planeta. $\mathrm{O}$ autor externa a idéia de que é preciso compreender o caráter humano no mundo, como a condição do mundo humano, que, ao longo da história moderna, se tornou a circunstância da era planetária, da própria sobrevivência da terra. Nesta mesma direção, Boff (1999) aponta como um dos sintomas da crise civilizacional um descaso e um descuido na salvaguarda de nossa casa comum, pois o cuidado envolve uma atitude de ocupação, preocupação, de responsabilização e de envolvimento afetivo com o outro, no caso do planeta, suplantado por interesse econômico, injustiças e violência.

Ao estudar este saber, veio-nos à imaginação a possibilidade de fazer com que os participantes despertassem em si mesmos esse sentimento de amor pela Mãe-terra. Então fizemos circular um globo terrestre pelas mãos de todos, em círculo, ao mesmo tempo em que se ouvia a música de Gui- 
lherme Arantes, "Planeta Água" (1995). Em pontos diferentes da sala, as facilitadoras pronunciaram, em voz alta, frases que se referiam à consciência de pertença à unidade planetária:

\author{
"Todo ser humano carrega em si o mundo" \\ "É necessário aprender a estar aqui no planeta" \\ "Nós somos uma unidade na diversidade" \\ "Consciência ecológica: habitar no planeta pela convivibilidade" \\ "Solidariedade e responsabilidade com todos os filhos da terra" \\ "Compreensão mútua"
}

Na parte final, todos deram as mãos e falaram: "nós somos a terra", seguida dos aplausos dos participantes. $\mathrm{O}$ grupo mostrava-se mais unido, à medida que, progressivamente, criava-se um campo relaxado e crescia o envolvimento das pessoas na elaboração do conhecimento.

Quinto saber: enfrentar as incertezas - simulação de imprevistos

A grande conquista da inteligência seria poder, enfim, se libertar da ilusão de prever o destino humano. O futuro permanece aberto e imprevisível. (MORIN, 2003, p.79).

Neste saber, o autor nos situa diante da imprevisibilidade, das incertezas que nos cercam e da impossibilidade, portanto, de certezas sobre os acontecimentos. É papel fundamental da educação, nesta óptica, preparar as mentes para o inesperado e seu enfrentamento.

Tardif (2002), no tocante a esse aspecto na prática pedagógica, assinala que, na maioria das vezes, os professores precisam tomar decisões e desenvolver estratégias de ação em plena atividade, sem se apoiar num "saber-fazer" técnico-científico que lhes permita controlar a situação com toda a certeza.

No grupo foi proposta a criação de situações inesperadas, nas quais as facilitadoras fingiram um desmaio, as luzes se apagaram, uma cobra de plástico foi lançada no meio da sala, e alguém entrou gritando "fogo, fogo"! Alguns participantes simularam entrar na cena, ao passo que outros permaneceram estáticos. Refletimos sobre algumas possibilidades de reações humanas diante do inesperado a partir do que aconteceu na turma - alguns 
diante do enunciado do título "Enfrentar as incertezas", imaginaram que era uma simulação e por isso não se mobilizaram; outros atuaram no sentido de participar da cena e outros permaneceram apáticos aos acontecimentos. Na vida, podemos nos abalar profundamente com as surpresas, agir de forma indiferente, reagir ativamente ou simplesmente nos tornar indiferentes.

Sexto saber: ensinar a compreensão - roda da compreensão

Compreender inclui um processo de empatia, de identificação e de projeção. Sempre intersubjetiva, a compreensão pede abertura, simpatia e generosidade (MORIN, 2003, p. 95).

Segundo Morin (2003), a missão espiritual da educação é ensinar a compreensão entre as pessoas como condição e garantia da solidariedade moral e intelectual da humanidade, pois, apesar dos avanços na tecnologia da comunicação, permanece a incompreensão tanto no plano individual como entre culturas e povos de origens culturais diferentes.

Para relacionar a ética da compreensão com o universo vivido, então com o grupo já integrado e aberto, sugerimos uma roda de embalo ao som da música Serra do Luar, interpretada por Leila Pinheiro (1997).

O conteúdo da letra foi refletido com os alunos estabelecendo relações com o pensamento do autor, o qual destaca a dimensão afetiva da atitude de compreender e o seu caráter de apreender em conjunto, abraçar junto, inclusive a incompreensão.

Sétimo saber: a ética do gênero humano - integração

\begin{abstract}
A antropoética compreende, assim, a esperança na completude da humanidade, como consciência e cidadania planetária (MORIN, 2003, p. 106).
\end{abstract}

O último saber referido por Morin diz respeito a uma antropoética do humano, consistindo numa decisão consciente e esclarecida de assumir a condição de indivíduo, espécie e sociedade na complexidade que ela encerra.

Ainda na roda de embalo, refletimos sobre o último saber apontada por Morin acerca da ética do gênero humano, que reflete uma consciência pessoal e da humanidade em nós, realizada pela democracia e estabeleci- 
mento da cidadania terrena. $\mathrm{O}$ autor ressalta o imperativo na livre expansão e expressão dos indivíduos, o desenvolvimento com propósito ético e político para o planeta e a integração da tríade indivíduo/sociedade/espécie, não apontando respostas prontas, mas traçando o caminho pelos passos que se vai desenvolvendo.

Ainda no abraço coletivo da grande roda, cada aluno expressou o seu sentimento em relação ao Seminário, referindo-se novos conhecimentos, nova maneira de ver as coisas, relação teoria-prática, repensar metodológico, vivência prática:

\footnotetext{
"Foi muito bom, vocês trouxeram um modo de se traduzir um livro altamente teórico e cheio de entrelinhas para o real" (Mestrando A).

"Um momento de repensar a metodologia tradicional e o que há de novo" (Mestrando B).

"Foi muito legal o tempo correu numa rapidez. Uma aula dessas faz a diferença" (Mestrando F).

"O grupo proporcionou uma vivência, um experimento muito prático do livro e foi muito bom" (Mestrando J).
}

No final de todo o Seminário cantou-se a música do Lulu Santos (1996), Como uma onda, representando uma transição entre a educação que temos e a que queremos estabelecer, cujo projeto pertence a cada um de nós, que se propõe atuar no campo da educação com um papel transformador.

\section{Reflexões conclusivas}

Procuramos neste ensaio articular os sete saberes necessários à educação do futuro, propostos por Edgar Morin, a prática pedagógica reflexiva e vivenciada, em Seminário temático sobre o tema. Para isso, pactuamos como metodologia trabalhar uma "práxis" pedagógica que favorecesse melhor compreensão dos participantes a respeito do pensamento desse autor. 
A realidade percebida, assim como o processo ensino-aprendizagem, é produto do enfrentamento do mundo concretizado e percebido pelo ser humano com toda a sua subjetividade inerente a cada um, que somente faz sentido à medida que brota e é guardado como experiência vivenciada, facilitando e otimizando a formação do ser humano.

Percebeu-se que houve a interação, assimilação e acomodação das experiências pelos participantes na metodologia proposta na formulação coletiva do conhecimento.

Este trabalho levanta o questionamento sobre a importância do desenvolvimento dos saberes da docência e da necessidade de o professor abrirse a novas estratégias que possibilitem a troca de conhecimentos e a interdisciplinaridade, como virtude que escuta a verdade do outro e se abre para novas idéias. Será possível uma prática pedagógica como nos mostra Morin no atual contexto de ensino? Como poderemos nós, alunos e professores, nos confrontar no enfrentamento cotidiano da vida e do ensinoaprendizagem como seres autonômos e críticos? Como romper com o cordão de repetições e acomodações que formam uma réplica de modelos cristalizados e autoritários na prática pedagógica?

Compreendemos que esta prática se faz pela ação do professor na condução dos grupos, na gestão das classes, na organização dos conteúdos, na articulação das disciplinas com o projeto pedagógico e o currículo, constituindo-se assim um saber próprio da docência. A formação de professores e, sobretudo, manter-se atualizado, aprendendo e reaprendendo a ser, a conviver, a fazer e a conhecer, constitui-se um decreto imutável para o saber fazer pedagógico alicerçado em novos valores e princípios.

\section{REFERÊNCIAS}

ALARCÃO, I. Professores reflexivos em uma escola reflexiva. Coleção questões da nossa época. Vol. 104. São Paulo: Cortez. 2003. p.100.

ANASTASIOU, L. G. C.; ALVES, L. P. Processo de ensinagem na universidade: pressupostos para as estratégias de trabalho em aula. Joinville, SC: Universille, 2004.

ARAÚJO, K. C. L. C. A construção dos saberes docentes: um olhar sobre a prática pedagógica dos professores iniciantes da educação superior. In: XIII ENCONTRO NACIONAL DE DIDÁTICA E PRÁTICA DE ENSINO, 13., 2002, Re cife. Anais... Programas e resumos: painéis e pôsteres. 
GOMES, A. M. A. et al. Os saberes e o fazer pedagógico:...

BOFF. L. Saber cuidar: ética do humano-compaixão pela terra. Petrópolis, Rio de Janeiro: Vozes. 1999. p. 199.

GILHERME ARANTES. Terra planeta água. Coleção Milennium. Vinte músicas do século XX. n. 532271-1 PolyGran. 1995. CD.

LEILA PINHEIRO. Coleção Obras Primas. n. 532693-2. Polygram . 1997. CD.

FAZENDA, I. C. A. (org.). 1998. Didática e Interdisciplinaridade. Campinas, São Paulo: Papirus. 1998. p.192.

FREIRE, P. Pedagogia do Oprimido. 8. ed. Rio de Janeiro: Paz e Terra. 1980. p.218.

. A educação na cidade. São Paulo: Cortez, 1999.

GOMES, A. M. A. O psicodrama aplicado ao grupo de trabalho de humanização no Hospital Geral de Fortaleza. Monografia (Especialização) - Instituto Cosmos de Psicodrama e Máscaras, Federação Brasileira de Psicodrama, Fortaleza. 2002. p.116.

LEAL, R. B. L. A discussão contemporânea do saber-fazer do professor. Universidade de Fortaleza. Programa de Capacitação e Atualização Pedagógica Permanente para Docentes da UNIFOR. Curso: A didática do ensino superior. Mimeo, 2004.

MORENO, J. L. Psicoterapia de grupo e psicodrama: introdução à teoria e à práxis. CESARINO FILHO, A. C. M. (trad.). São Paulo: Editora Mestre Jou, 1959.

MORIN, E. A cabeça bem-feita: repensar a reforma, reformar o pensamento. Tradução Eloá Jacobina. 9. ed. Rio de Janeiro: Bertrand Brasil. 2004. p.128.

Os sete saberes necessários à educação do futuro. Tradução de Catarina Eleonora F. da Silva e Jeanne Sawaya; revisão técnica de Edgard de Assis Carvalho. 8. ed. São Paulo: Cortez, Brasília, DF: UNESCO. 2003. p. 118.

PERRENOUD, P. A prática reflexiva no ofício de professor: profissionalização e razão pedagógica. Tradução Cláudia Schilling. Porto Alegre: Artmed Editora, 2002.

PIMENTA, S. G; ANASTASIOU, L. G. C. Docência no ensino superior. São Paulo: Cortez, 2002. p. 279.

ROMAÑA, M. A. Psicodrama pedagógico: método educacional psicodramático. 2. ed. Campinas, São Paulo: Papirus, 1987.

. Do psicodrama pedagógico à pedagogia do drama. Campinas: Papirus. 1996.

SCHON, D. A. Educando o profissional reflexivo: um novo design para o ensino e a aprendizagem. Tradução Roberto Cataldo Costa. Porto Alegre: Artes Médicas, 2000.

SILVA, W. R. A construção/desconstrução do saber no contexto da prática de ensino. n: XIII ENCONTRO NACIONAL DE DIDÁTICA E PRÁTICA DE ENSINO, 13., 2002, Re cife. Anais... Programas e resumos: painéis e pôsteres. 
GOMES, A. M. A. et al. Os saberes e o fazer pedagógico:...

TARDIF, M. Saberes docentes e formação profissional. 2. ed. Petrópolis, Rio de Janeiro: Vozes. 2002

Texto recebido em 07 out. 2005

Texto aprovado em 16 jan. 2006 